\title{
Periodic array of complementary artificial magnetic conductor metamaterials-based multiband antennas for broadband wireless transceivers
}

ISSN 1751-8725

Received on 25th January 2016

Revised on 19th May 2016

Accepted on 9th June 2016

doi: 10.1049/iet-map.2016.0069

www.ietdl.org

\section{Mohammad Alibakhshi-Kenari ${ }^{1}$, Mohammad Naser-Moghadasi ${ }^{1}{ }^{凶}$, Ramzan Ali Sadeghzadeh $^{2}$, Bal S. Virdee ${ }^{3}$, Ernesto Limiti ${ }^{4}$ \\ ${ }^{1}$ Faculty of Engineering, Science and Research Branch, Islamic Azad University, Tehran, Iran \\ ${ }^{2}$ Faculty of Electrical Engineering, K.N. Toosi University of Technology, Tehran, Iran \\ ${ }^{3}$ Center for Communications Technology, Faculty of Life Sciences and Computing, London Metropolitan University, London N7 8DB, UK ${ }^{4}$ Dipartimento di Ingegneria Elettronica, Università degli Studi di Roma Tor Vergata, Via del Politecnico 1, 00133 Roma, Italy 凶-mail: mn.moghaddasi@srbiau.ac.ir}

\begin{abstract}
This study presents the empirical results of a low-profile light-weight antenna based on a periodic array of the complementary artificial magnetic conductor metamaterial structure, which is realised by loading the antenna with Eshaped slits and inductive microstrip lines grounded using metallic via-holes. The finalised prototype antenna operates over a broadband of $0.41-4.1 \mathrm{GHz}$, which corresponds to a fractional bandwidth of $165.84 \%$, and has dimensions of $40 \times 35 \times 1.6 \mathrm{~mm}^{3}$ or $0.054 \lambda_{0} \times 0.047 \lambda_{0} \times 0.0021 \lambda_{0}$, where $\lambda_{0}$ is free-space wavelength at operating frequency of $410 \mathrm{MHz}$. The finalised antenna has a peak gain and radiation efficiency of $4.45 \mathrm{dBi}$ and $85.8 \%$, respectively, at $2.76 \mathrm{GHz}$. At the lower operating frequency of $410 \mathrm{MHz}$, the gain and radiation efficiency are $1.05 \mathrm{dBi}$ and $32.5 \%$, respectively, which is normally highly challenging to realise with very small antennas. The planar nature of antenna enables easy integration with wireless transceivers.
\end{abstract}

\section{Introduction}

Rapid development of wireless communication systems is bringing about a wave of new wireless devices and systems to meet the demands of multimedia applications [1,2]. Multi-frequency and multi-mode devices such as cellular phones, wireless local area networks and wireless personal area networks place several demands on the antennas [3, 4]. Primarily, the antennas need to have high gain, small physical size, broad bandwidth, versatility, embedded installation and so on. In particular, the impedance bandwidth, radiation patterns, gains and efficiencies are the most important factors that affect the application of antennas in contemporary and future wireless communication systems [5].

Research into metamaterials based on periodic unit cells has grown rapidly with the discovery of left-handed metamaterials [6, 7]. The transmission-line metamaterial (TL-MTM) technology has been applied to various types of antennas, i.e. compact antennas [8-12], leaky-wave antennas [13] and series-fed antenna arrays [14]. In [7], the bandwidth and radiation characteristics of monopole antennas, which are based on T- and F-shaped radiators, are loaded with split-ring resonators of various sizes. In [9-12], the antenna designs are based on composite right/left-handed transmission-line unit cells implemented by engraving slits on the radiating patch that is loaded with spiral inductors. This technology brings enabling capabilities, in particular: (i) the ability to strongly manipulate the propagation of electromagnetic (EM) waves in confined small structure; and (ii) the freedom to precisely and systematically determine a broad set of parameters including the bandwidth, gain, efficiency and physical size. Therefore, TL-MTMs appear to be a suitable candidate for developing electrically small antennas for multiband applications.

In this paper, a new artificial magnetic conductor (AMC) structure has been proposed for a low-profile antenna that offers enhanced gain performance, reduced back-lobe level radiation, wideband operation and small physical footprint. The ground plane of the antenna acts like a reflector for the radiation impinging on its surface; however, the phase of radiation impinging on conductor's surface is reversed which can interfere destructively with the radiated waves from the antenna. This can significantly reduce the antenna's radiation efficiency. However, if the reflected radiation is in-phase (i.e. $0^{\circ}$ ) or with phase change in the range $\pm 90^{\circ}$, then there will be a constructive interference of reflected wave with the radiated wave. This feature is exploited in this paper to improve the radiation characteristics of the antenna over its operating frequency range where the incoming radiations are reflected at angle between $\pm 90^{\circ}$. To accomplish this, the ground plane of the proposed antenna is loaded with periodic array of E-shaped complementary AMC (CAMC) and grounded inductive lines to realise metamaterial properties. The work is organised as follows. Section 2 describes the design process of implementing the proposed antennas and presents the simulated and measured results of the prototype antennas. Finally, the work is concluded in Section 3.

\section{AMC surfaces}

In the analysis, the cross-section of the antenna structure in Fig. 1 is considered. A cavity is formed by the perfect electric conductor (PEC) ground plane and a partially reflective surface (PRS) placed at a distance $(h)$ as described in [15]. The PRS is assumed to be a homogeneous surface in the analysis. The antenna function can be described by following the paths of the waves undergoing multiple reflections inside the cavity. Phase shifts are introduced by the path length, the PEC and the reflection coefficient of the PRS. Following the paths of the direct and the reflected waves and taking into account the various phase shifts introduced to them, the resonance condition of the cavity can be easily derived. The PEC introduces a phase shift of $\pi$. The resonance condition can be easily derived by imposing the phase difference of the transmitted waves to be zero. The PRS introduces a phase shift equal to the phase of its transmission coefficient, $\phi_{\mathrm{T}}$. If $\phi_{2}-\phi_{1}$ is the phase 


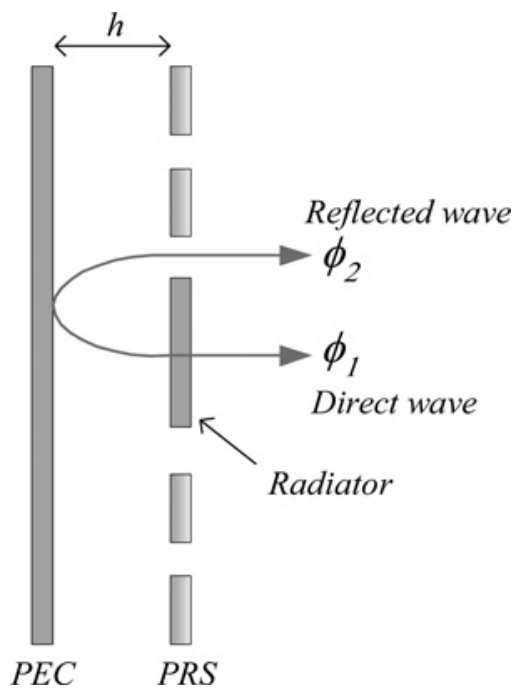

Fig. 1 Antenna cross-section where a resonant cavity is created by PEC and PRS

difference between direct and reflected waves, the resonance condition is written as follows:

$$
\phi_{2}-\phi_{1}=2 \phi_{\mathrm{T}}-\frac{2 \pi}{\lambda} 2 h-\pi=2 N \pi, \quad N=0,1,2 \ldots
$$

This resonant cavity behaves as a perfect magnetic conductor (at normal incidence) since it reflects normal incident waves with zero phase shift. Consequently, placing a simple point source in close proximity to the PRS would result in constructive interference between direct and reflected waves at the cavity resonance.

\subsection{Antenna \#1}

The geometry of Antenna \#1 structure consists of two square radiation patches of different dimensions that are interconnected to each other with a microstrip line. Two inverted L-shaped inductive lines are attached between the interconnecting line and the input feed-line plane, and are grounded at the bends using metallic via-holes to implement the shunt left-handed inductance that reflects the incident waves with reflection phase of near zero degrees. This proposed structure helps to enhance the antenna's impedance bandwidth and also determines the antenna's unidirectional radiation.

The E-shaped CAMC unit cells create a resonance cavity in the antenna structure. As explained above, the distance between PEC and PRS must be such that the reflected waves through the PRS into space have equal phases in the normal direction. The resonance condition of the cavity is determined by (1). The E-shaped CAMC unit cells essentially concentrate the EM fields and currents near the antenna structure to effectively prevent the fields from spreading along the antenna's ground plane and therefore contribute towards unwanted coupling. This technique should allow implementation of small antennas with minimal mutual coupling which is important to decorrelate multipath channels in small cellular systems.

Disposed on either side of the two square radiating patches are rectangular conductors that are loaded with periodic array of E-shaped slits, as shown in Fig. 2a. The slits act as CAMC unit cells exhibiting series left-handed capacitances [9-12]. Details of this technique are described in $[16,17]$ where an AMC surface is created using square and rectangular loop slits. The AMC surfaces exhibit high surface impedance, due to which the magnetic field tangential to the surface vanishes. Hence, the structure reflects incident waves with zero or near zero phase shift. The proposed
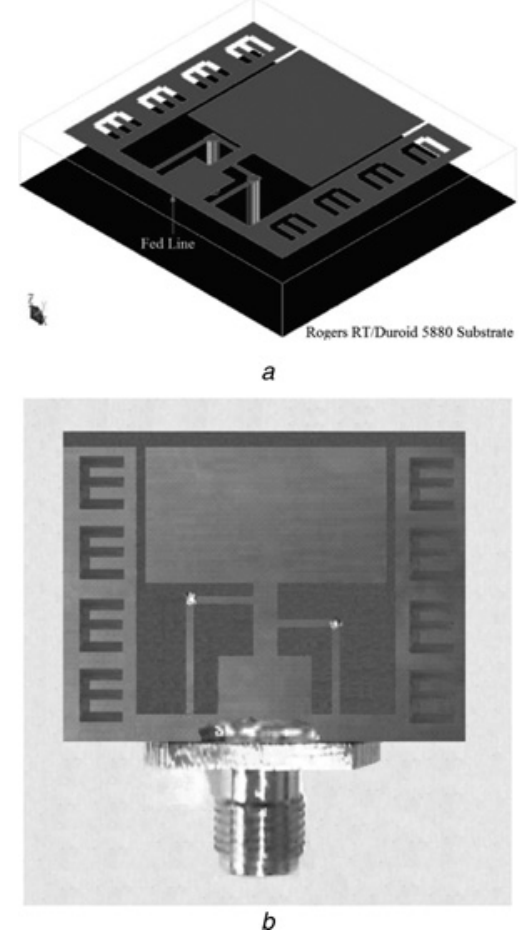

Fig. 2 Perspective view and fabricated prototype of Antenna \#1 $a$ Perspective view of Antenna \#1

$b$ Fabricated prototype of Antenna \#1. Dimensions are given in Table 3

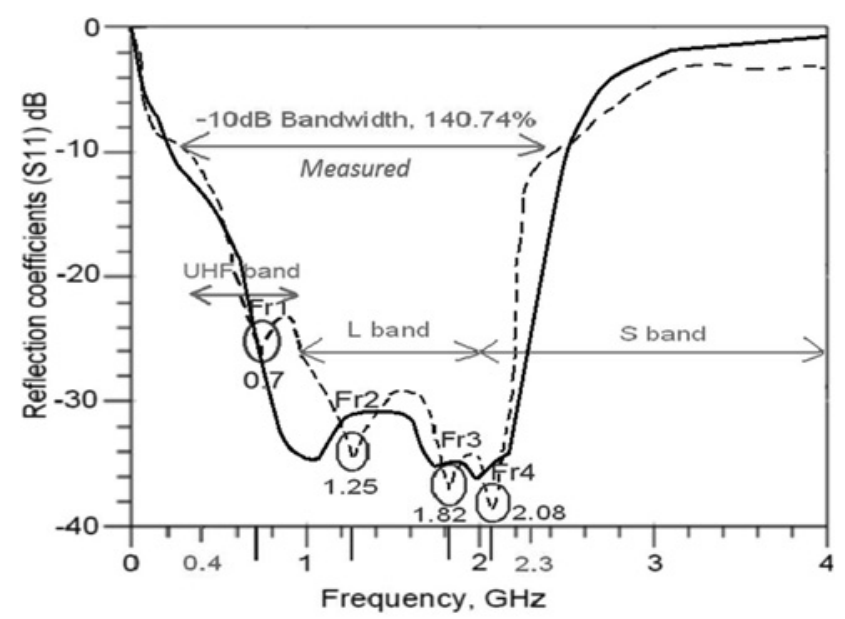

a

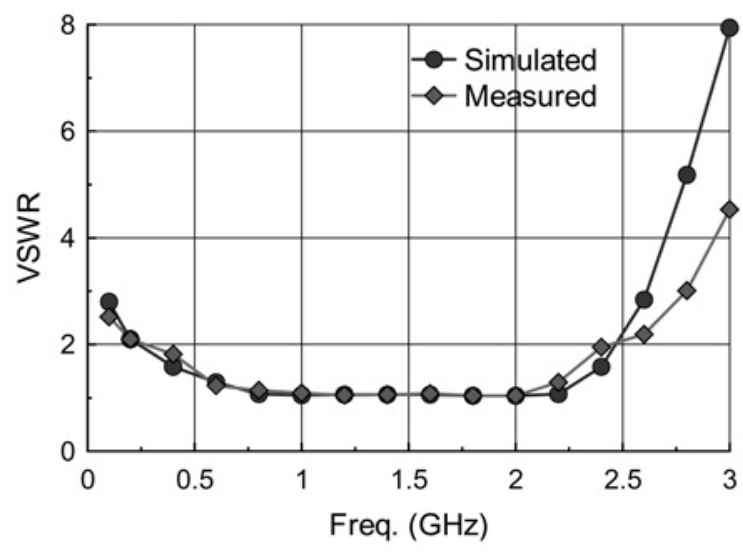

$b$

Fig. 3 Simulated and measured reflection coefficient and VSWR of Antenna \#1

$a$ Simulated (solid line) and measured (dashed line) reflection-coefficient response $b$ Simulated (circular line) and measured (square line) voltage standing wave ratio response 


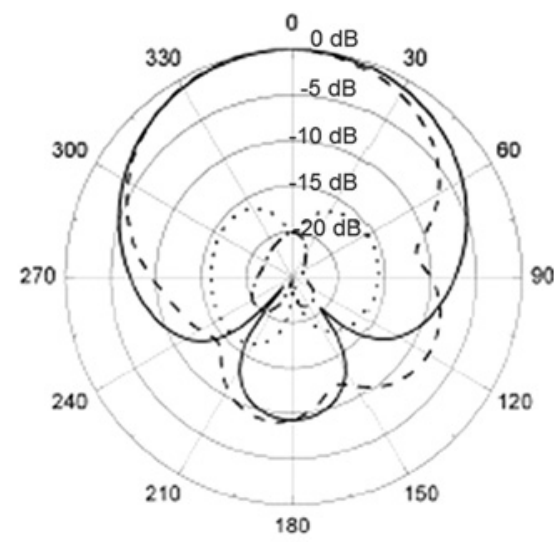

(a) $400 \mathrm{MHz}$

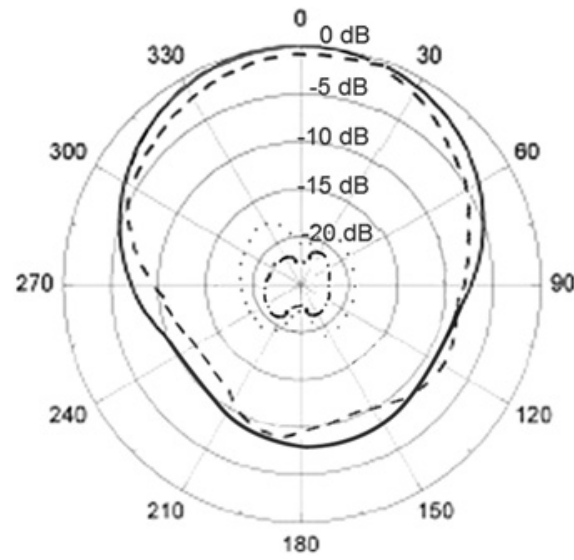

(a) $2.08 \mathrm{GHz}$

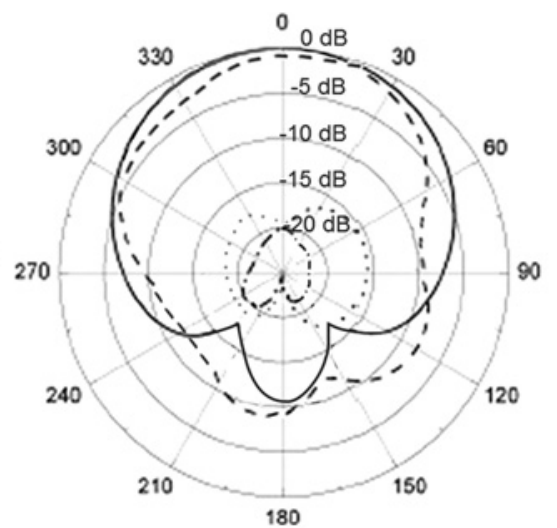

(a) $1.25 \mathrm{GHz}$

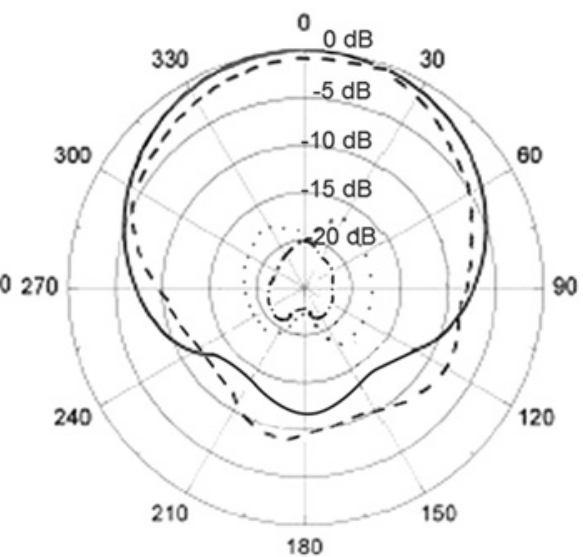

(a) $2.3 \mathrm{GHz}$

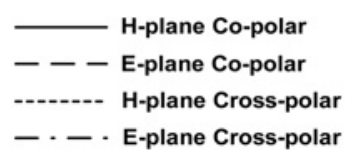

Fig. 4 Measured 2D radiation patterns of Antenna \#1 at various operating frequencies of 0.4, 1.25, 2.08 and 2.3 GHz

antenna is excited through an SMA connector located at the lower end of the smaller square patch. The CAMCs unit cells produce fringing fields that make the effective dimensions of the patch greater than its physical dimensions. The size and number of CAMC unit cells were determined through optimisation using three-dimensional (3D) full-wave EM simulator so that CAMC reflects incoming radiations at zero degrees. The goal here was to design and implement the antenna within an area of $40 \mathrm{~mm}^{2}$. It was necessary to optimise the antenna's performance in terms of its impedance bandwidth and radiation characteristics. The antenna is constructed on Rogers RT/Duroid 5880 substrate with a dielectric permittivity $\left(\varepsilon_{r}\right)$ and loss tangent $(\tan \delta)$ of 2.2 and 0.0009 , respectively. The substrate has a height $(h)$ of $1.6 \mathrm{~mm}$. The dimensions of Antenna \#1 are: $27 \times 35 \times 1.6 \mathrm{~mm}^{3}$ or $0.036 \lambda_{0} \times 0.046 \lambda_{0} \times 0.0021 \lambda_{0}$ in terms of free-space wavelength at $400 \mathrm{MHz}$.

Although the single E-shaped slit is a narrowband resonant structure, the extension in the bandwidth is achieved by electromagnetically coupling multiple E-shaped slits, as shown in Fig. 2, which is analogous to cascading together several identical narrowband resonators [9-11]. The simulated and measured reflection coefficient and Voltage Standing Wave Ration (VSWR) response in Fig. 3 confirm that the antenna exhibits an impedance bandwidth of $1.9 \mathrm{GHz}$ from 0.4 to $2.3 \mathrm{GHz}$ for $S_{11}<-10 \mathrm{~dB}$, and its measured VSWR $<2$ between 0.4 and $3.0 \mathrm{GHz}$. The antenna resonates in its operating range at four distinct frequencies, i.e.
700, 1250, 1820 and $2080 \mathrm{MHz}$. The proposed antenna operates over ultra high frequency (UHF), L- and S-bands. Simulations and measurements were carried out using High Frequency Simulator Structure (HFSS) software and Agilent N5224A vector network analyser, respectively. The proposed antennas were fabricated using standard manufacturing techniques.

Agilent N5224A vector network analyser used to characterise the antenna was calibrated with a standard short-open-load thru calibration procedure. The simulated and measured results presented agree well with each other, showing the accuracy of the model is valid. The radiation pattern of the antenna was measured in a standard anechoic chamber. The antenna gain was measured using the comparative method that involves measuring the signal received by a reference antenna and by the antenna under test (AUT), and determining the relative difference in the gain of both antennas when both the reference antenna and AUT are working in the received mode [18]. With this information, the gain of the test antenna is determined.

The measured radiation characteristics of the antenna at the different operating frequencies are shown in Fig. 4. The antenna radiates unidirectionally in both $E$ - and $H$-planes. The cross-polarisation is less than $-20 \mathrm{~dB}$ for both planes, and the radiation characteristics essentially remain stable over the antenna's operating frequency range. The simulated and measured gain and radiation efficiency of Antenna \#1 is shown in Fig. 5. It is evident that the measured gain and efficiency have a peak of 


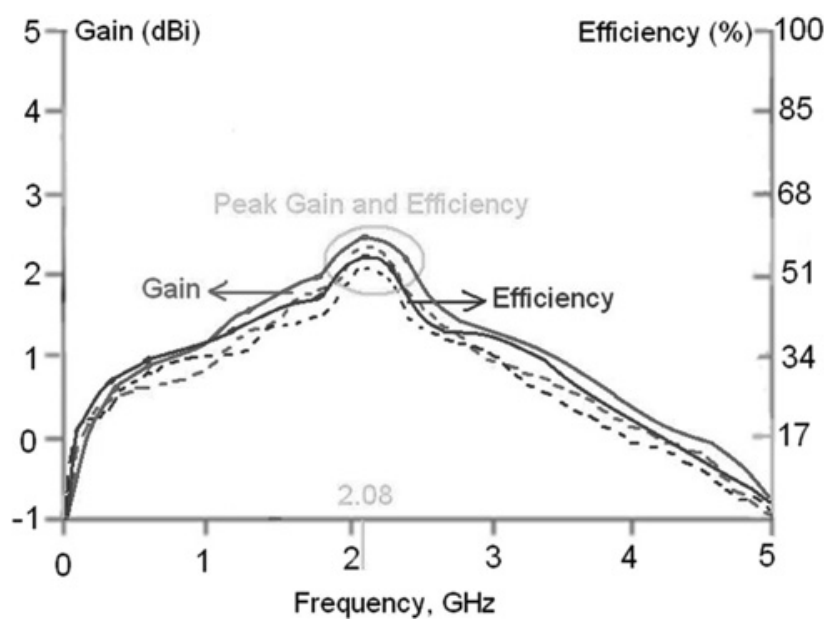

Fig. 5 Simulated (solid line) and measured (dashed line) gain and efficiency response of Antenna \#1

Table 1 Radiation characteristics of Antenna \#1

\begin{tabular}{|c|c|c|c|c|c|c|c|}
\hline \multicolumn{2}{|c|}{ Frequency, $\mathrm{GHz}$} & \multirow{2}{*}{$\begin{array}{c}f_{\text {start }}: \\
0.4\end{array}$} & \multirow{2}{*}{$\begin{array}{l}f_{r 1}: \\
0.7 \\
0.92 \\
34.7\end{array}$} & \multirow{2}{*}{$\begin{array}{l}f_{r 2}: \\
1.25 \\
1.53 \\
40.1\end{array}$} & \multirow{2}{*}{$\begin{array}{c}f_{r 3}: \\
1.82 \\
2.0 \\
46.4\end{array}$} & \multirow{2}{*}{$\begin{array}{c}\boldsymbol{f}_{\mathbf{r 4}}: \mathbf{2 . 0 8} \\
(\max ) \\
2.48 \\
54.7\end{array}$} & \multirow{2}{*}{$\begin{array}{c}f_{\text {end: }}: \\
2.3 \\
2.25 \\
51.5\end{array}$} \\
\hline simulated & $\begin{array}{c}\text { gain, } d B i \\
\text { efficiency, } \\
\%\end{array}$ & & & & & & \\
\hline measured & $\begin{array}{c}\text { gain, dBi } \\
\text { efficiency, } \\
\%\end{array}$ & $\begin{array}{c}0.5 \\
28.7\end{array}$ & $\begin{array}{l}0.73 \\
31.1\end{array}$ & $\begin{array}{c}1.2 \\
37.3\end{array}$ & $\begin{array}{l}1.88 \\
44.9\end{array}$ & $\begin{array}{l}2.21 \\
51.4\end{array}$ & $\begin{array}{c}2.0 \\
49.6\end{array}$ \\
\hline
\end{tabular}

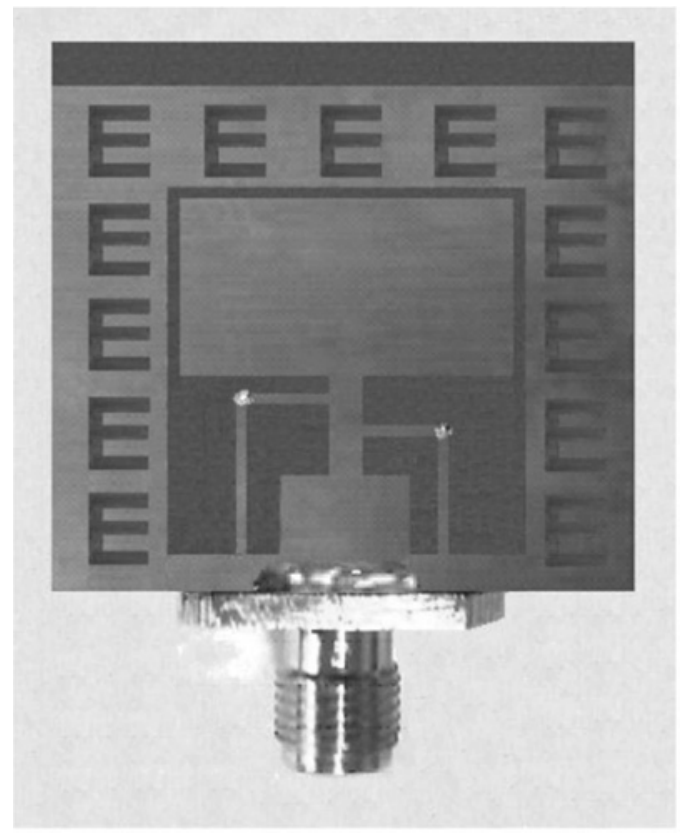

Fig. 6 Fabricated prototype of Antenna \#2. Dimensions are given in Table 3

$2.21 \mathrm{dBi}$ and $51.4 \%$, respectively, at the fourth resonant mode of $2.08 \mathrm{GHz}$. Salient features of Antenna \#1 are tabulated in Table 1.

\subsection{Antenna \#2}

Besides the requirement of compact size, the proposed antenna needs to possess wide bandwidth and good radiation characteristics such as

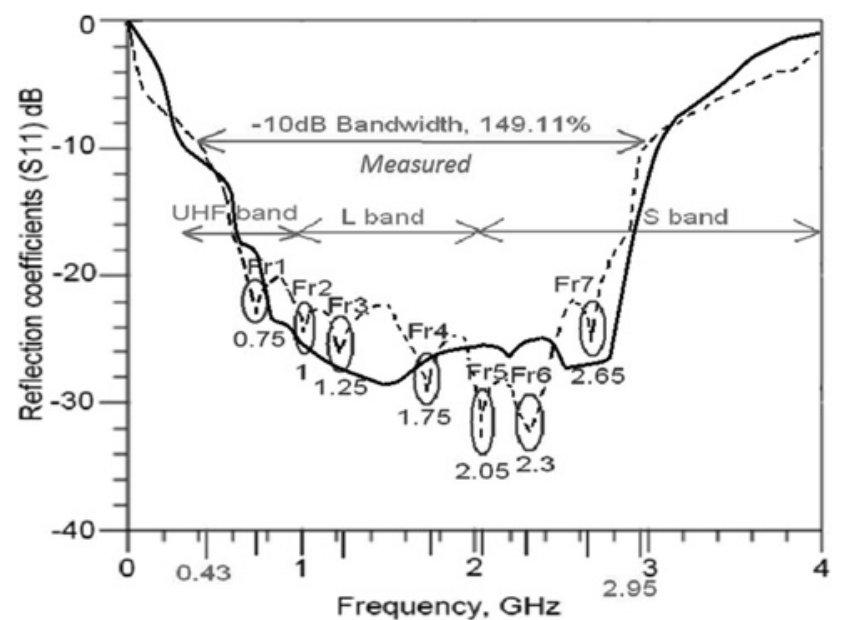

a

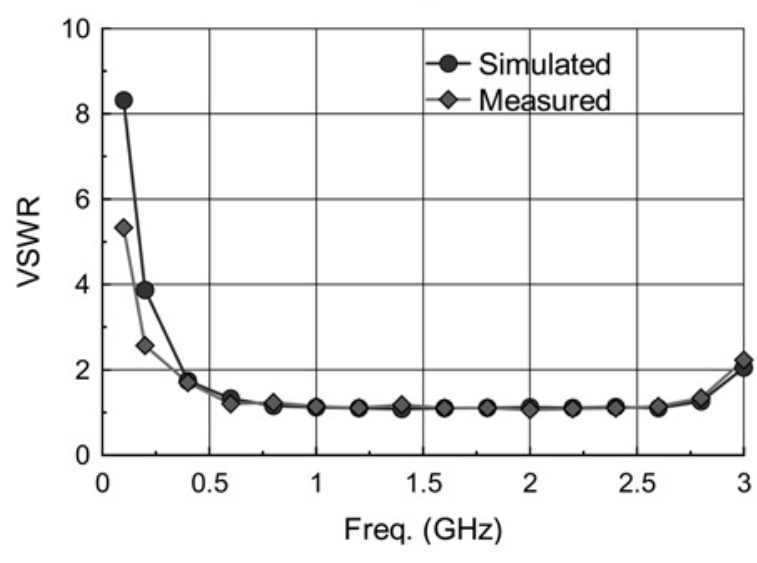

b

Fig. 7 Simulated and measured reflection coefficients and VSWR of Antenna \#2

$a$ Simulated (solid line) and measured (dashed line) reflection-coefficient response $b$ Simulated (circular line) and measured (square line) voltage standing wave ratio response

gain and efficiency performance. These characteristic features are conventionally achieved by increasing the effective cross-sectional area of antenna. The impedance bandwidth and radiation characteristics of the proposed antenna were improved by simply employing five additional E-shaped CAMC unit cells that are located above the larger patch, as shown in Fig. 6, with the advantage of not affecting the radiating patch's physical dimensions. The impedance bandwidth and radiation characteristics of Antenna \#2 are shown in Figs. 7-9. Antenna \#2 has a size of $33 \times 35 \times 1.6 \mathrm{~mm}^{3}$ or $0.047 \lambda_{0} \times 0.050 \lambda_{0} \times 0.0022 \lambda_{0}$, where the free-space wavelength is $430 \mathrm{MHz}$.

The measured impedance bandwidth in Fig. 7 extends from 0.43 to $2.95 \mathrm{GHz}$ for $S_{11}<-10 \mathrm{~dB}$, which corresponds to $149.11 \%$; thus covering UHF, L- and S-bands. The antenna has VSWR $<2$ between 0.4 and $3.0 \mathrm{GHz}$. The antenna resonates in its operating range at the following frequencies: $0.75,1,1.25,1.75,2.05,2.30$ and $2.65 \mathrm{GHz}$. The antenna radiates unidirectionally in both $E$ - and $H$-planes, as shown in Fig. 8, and its radiation characteristics are stable over the antenna's operating frequency range. Fig. 9 shows that the antenna's simulated and measured gain and radiation efficiency performance have a peak value of $3.12 \mathrm{dBi}$ and $52.7 \%$, respectively, at the sixth resonant mode of $2.30 \mathrm{GHz}$. Salient features of the Antenna \#2 are tabulated in Table 2.

\subsection{Antenna \#3}

The next iteration is Antenna \#3, which includes five additional E-shaped CAMCs unit cells located above the larger square patch. 

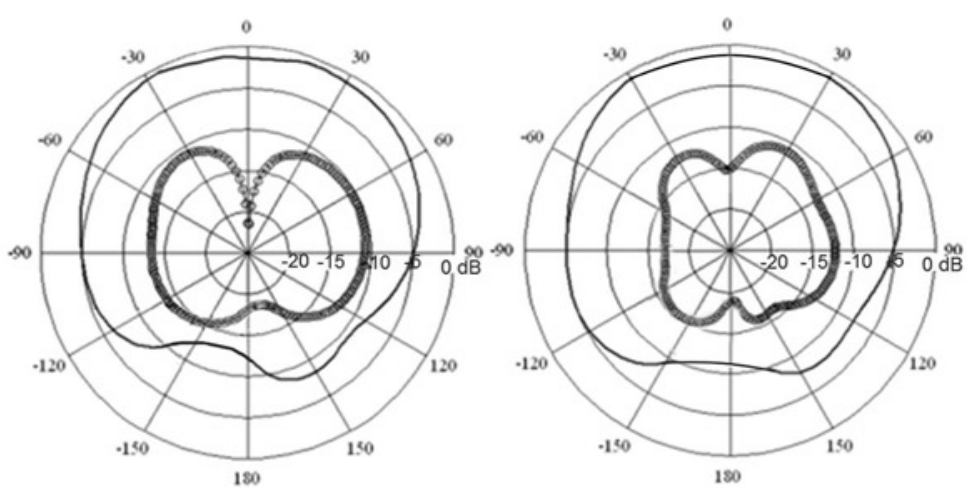

E-plane (faint line: Co-polar, and bold line: X-polar)

H-plane (faint line: Co-polar, and bold line: X-polar)
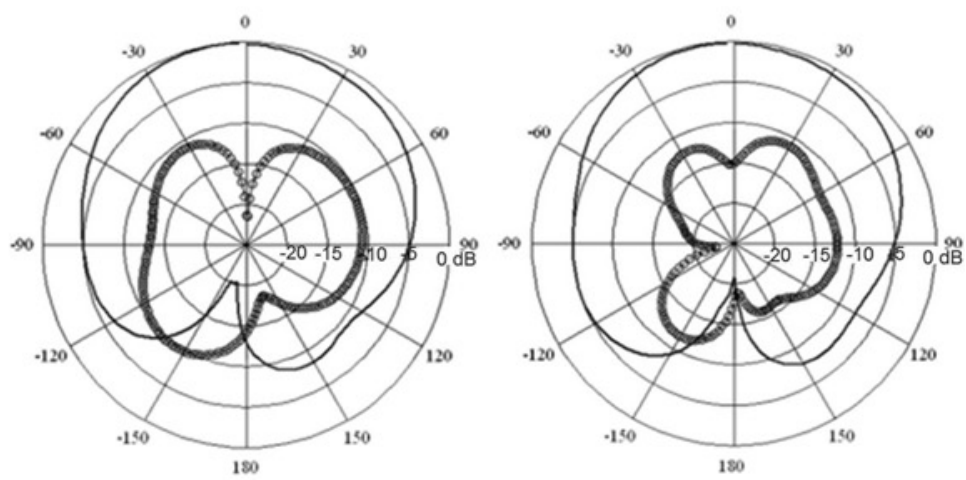

E-plane (faint line: Co-polar, and bold line: X-polar)

H-plane (faint line: Co-polar, and bold line: X-polar)
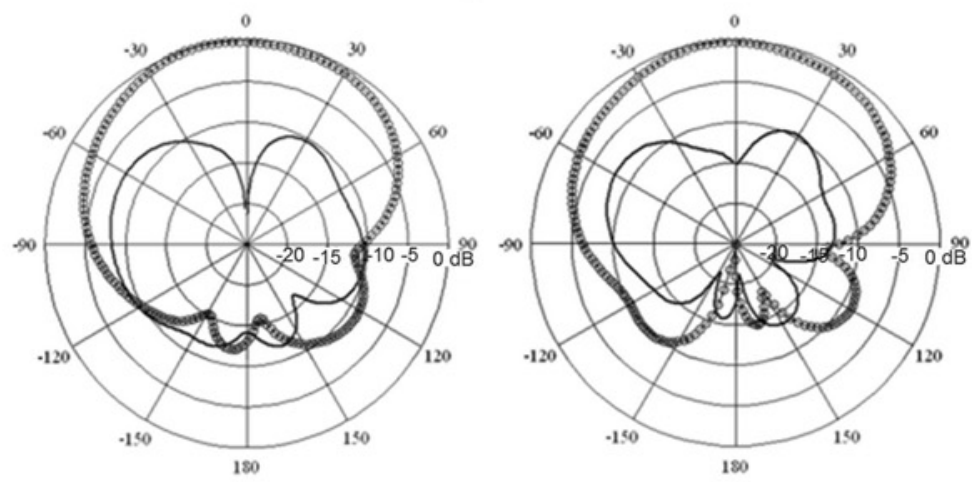

E-plane (bold line: Co-polar, and faint line: X-polar)

H-plane (bold line: Co-polar, and faint line: X-polar)

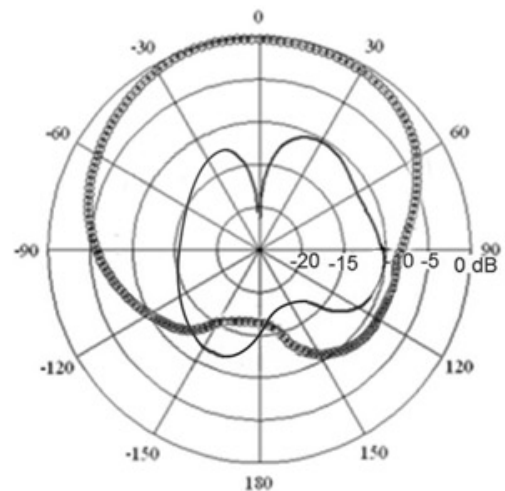

E-plane (bold line: Co-polar, and faint line: X-polar)

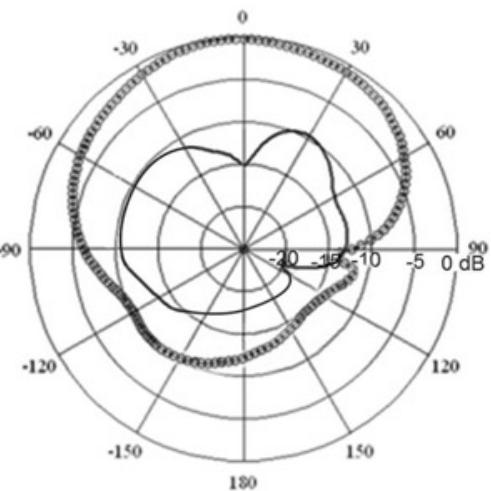

H-plane (bold line: Co-polar, and faint line: $\mathrm{X}$-polar)

Fig. 8 Measured 2D radiation patterns of Antenna \#2 at various operating frequencies of a $430 \mathrm{MHz}$

b $1 \mathrm{GHz}$

c $2.3 \mathrm{GHz}$

$d 2.95 \mathrm{GHz}$ 


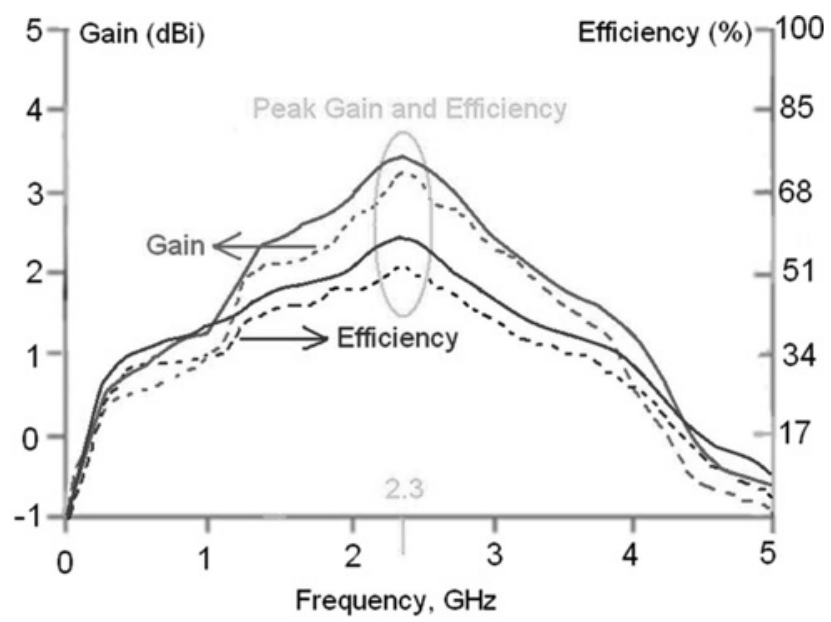

Fig. 9 Simulated (solid line) and measured (dashed line) gain and efficiency response of Antenna \#2

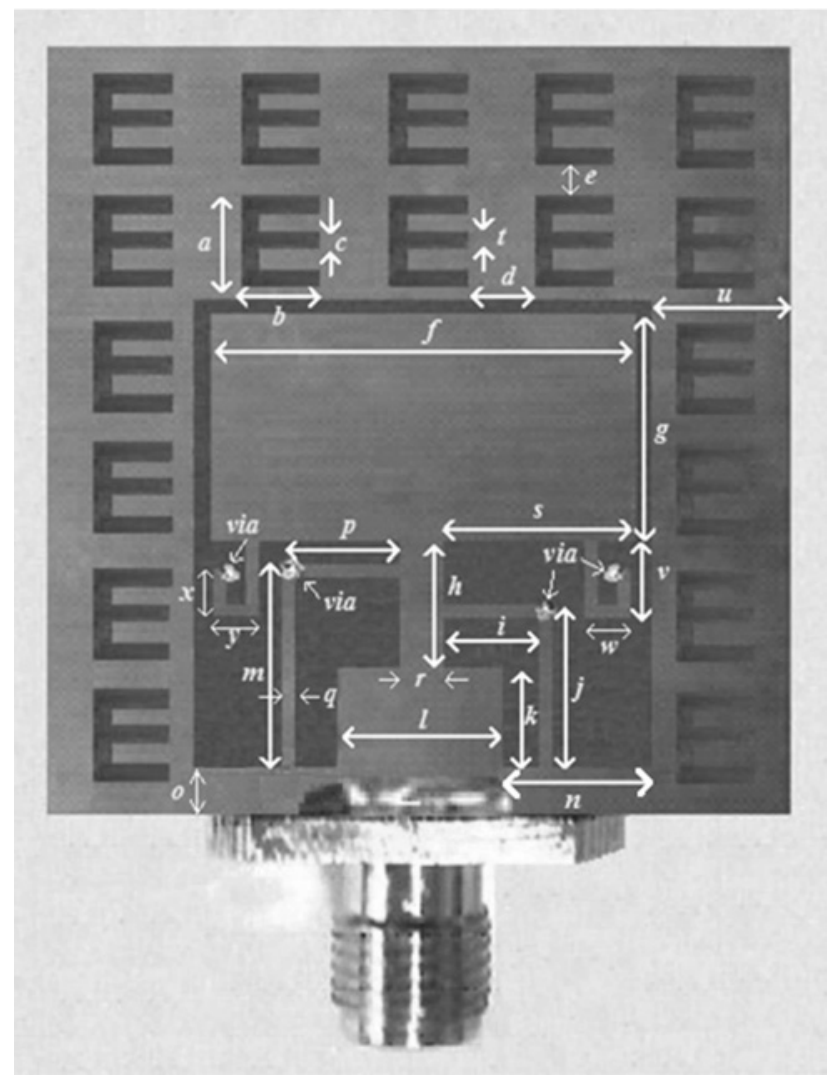

Fig. 10 Fabricated prototype of Antenna \#3

Also included are two inductive lines connected to the larger patch at the lower edge to enhance the impedance bandwidth of the antenna. Ends of these inductive lines are connected to the ground plane by the metallic via-holes, as shown in Fig. 10. Parameters defining Antenna \#3 are labelled alphabetically in Fig. 10, and the corresponding values are given in Table 3 . The overall size of the antenna is $40 \times 35 \times 1.6 \mathrm{~mm}^{3}$, which is equivalent to $0.054 \lambda_{0} \times$ $0.047 \lambda_{0} \times 0.0021 \lambda_{0}$ at $410 \mathrm{MHz}$.

The simulated and measured reflection coefficient and VSWR response of Antenna \#3 are shown in Fig. 11. The antenna has an experimental impedance bandwidth of $3.69 \mathrm{GHz}$ from 0.41 to 4.1 $\mathrm{GHz}$ for VSWR $<1.5$ that corresponds to a fractional bandwidth of $165.84 \%$. Antenna \#3 resonates in its operating range at $600 \mathrm{MHz}$, $1.15 \mathrm{GHz}, 1.65 \mathrm{GHz}, 2.41 \mathrm{GHz}, 2.76 \mathrm{GHz}, 3.23 \mathrm{GHz}, 3.79 \mathrm{GHz}$, $4.01 \mathrm{GHz}$ and $4.085 \mathrm{GHz}$. The antenna is useful in the frequency range covering UHF to C-band.

Also, since we have proposed a UWB antenna, the time-domain characteristic like group delay, which is defined by (2), for help in justifying antenna for UWB applications is presented in Fig. $11 c$

$$
D(\omega) \triangleq-\frac{\mathrm{d} \theta(\omega)}{\mathrm{d}(\omega)}
$$

The antenna radiates unidirectionally in both $E$ - and $H$-planes. The cross-polarisation is less than $-20 \mathrm{~dB}$ for both planes, and the radiation characteristics essentially remain constant over the antenna's operating frequency range, as shown in Fig. $11 d$.

The simulated and measured gain and radiation efficiency of Antenna \#3 are shown in Fig. 11e. It is evident that the measured gain and efficiency performance have a peak value of $4.45 \mathrm{dBi}$ and $85.8 \%$, respectively, at the fifth resonant mode of $2.76 \mathrm{GHz}$. Salient features of the Antenna \#3 are tabulated in Table 4.

The criteria used to determine the number CAMC unit cells depend on a tradeoff between the antenna dimensions, impedance bandwidth and radiation characteristics. The overall goal here was to design and implement an antenna that fitted within an area of $40 \mathrm{~mm}^{2}$ and exhibited an ultra-wide bandwidth with good unidirectional radiation patterns. The number and size of unit cells were determined through optimisation using HFSS. Figs. 3, 7 and 11 show the reflection coefficients of the antennas with increasing number of CAMC unit cells from 8 to 18. Eighteen unit cells provide the impedance bandwidth of $0.41-4.1 \mathrm{GHz}$ for a reflection coefficient of $-10 \mathrm{~dB}$. Therefore, eighteen unit cells were used here in the final antenna design. Salient characteristics of the three antennas are summarised in Table 5. It is evident that Antenna \#3 when compared with Antenna \#1 has significantly improved impedance bandwidth, gain and efficiency by 17.8, 101.4 and $66.9 \%$, respectively. This is attributed to the ten CAMC unit cells that extend the effective aperture of Antenna \#3.

The antenna efficiency was measured in an anechoic chamber by feeding power to the antenna feed and measuring the strength of the radiated EM field in the surrounding space. The efficiency was calculated by taking the ratio of the radiated power to the input power of the antenna. The gain of the antenna was measured using the standard gain comparison technique where pre-calibrated standard gain antenna was used to determine the absolute gain of the AUT.

To validate the design procedure, the proposed antennas specifications have compared with some of recent antennas in Table 6.

Table 2 Radiation characteristics of Antenna \#2

\begin{tabular}{|c|c|c|c|c|c|c|c|c|c|c|}
\hline \multicolumn{2}{|c|}{ Frequency, $\mathrm{GHz}$} & \multirow{2}{*}{$\begin{array}{c}f_{\text {start }}: 0.43 \\
0.8\end{array}$} & \multirow{2}{*}{$\frac{f_{r 1}: 0.75}{0.95}$} & \multirow{2}{*}{$\frac{f_{r 2}: 1}{1.22}$} & \multirow{2}{*}{$\frac{f_{r 3}: 1.25}{2.2}$} & \multirow{2}{*}{$\begin{array}{c}f_{r 4}: 1.75 \\
2.4\end{array}$} & \multirow{2}{*}{$\begin{array}{c}f_{r 5}: 2.05 \\
3.05\end{array}$} & \multirow{2}{*}{$\begin{array}{c}f_{r 6}: 2.3(\max ) \\
3.35\end{array}$} & \multirow{2}{*}{$\frac{f_{r 7}: 2.65}{3.0}$} & \multirow{2}{*}{$\frac{f_{\text {end }}: 2.95}{2.32}$} \\
\hline simulated & gain, $\mathrm{dBi}$ & & & & & & & & & \\
\hline & efficiency, \% & 34.7 & 36.3 & 38.4 & 43.1 & 48.8 & 53.1 & 56.0 & 50.4 & 45.9 \\
\hline \multirow[t]{2}{*}{ measured } & gain, dBi & 0.65 & 0.8 & 1.0 & 2.0 & 2.28 & 2.75 & 3.12 & 2.86 & 2.15 \\
\hline & efficiency, \% & 32.0 & 33.2 & 34.5 & 40.7 & 44.3 & 48.5 & 52.7 & 47.1 & 39.8 \\
\hline
\end{tabular}



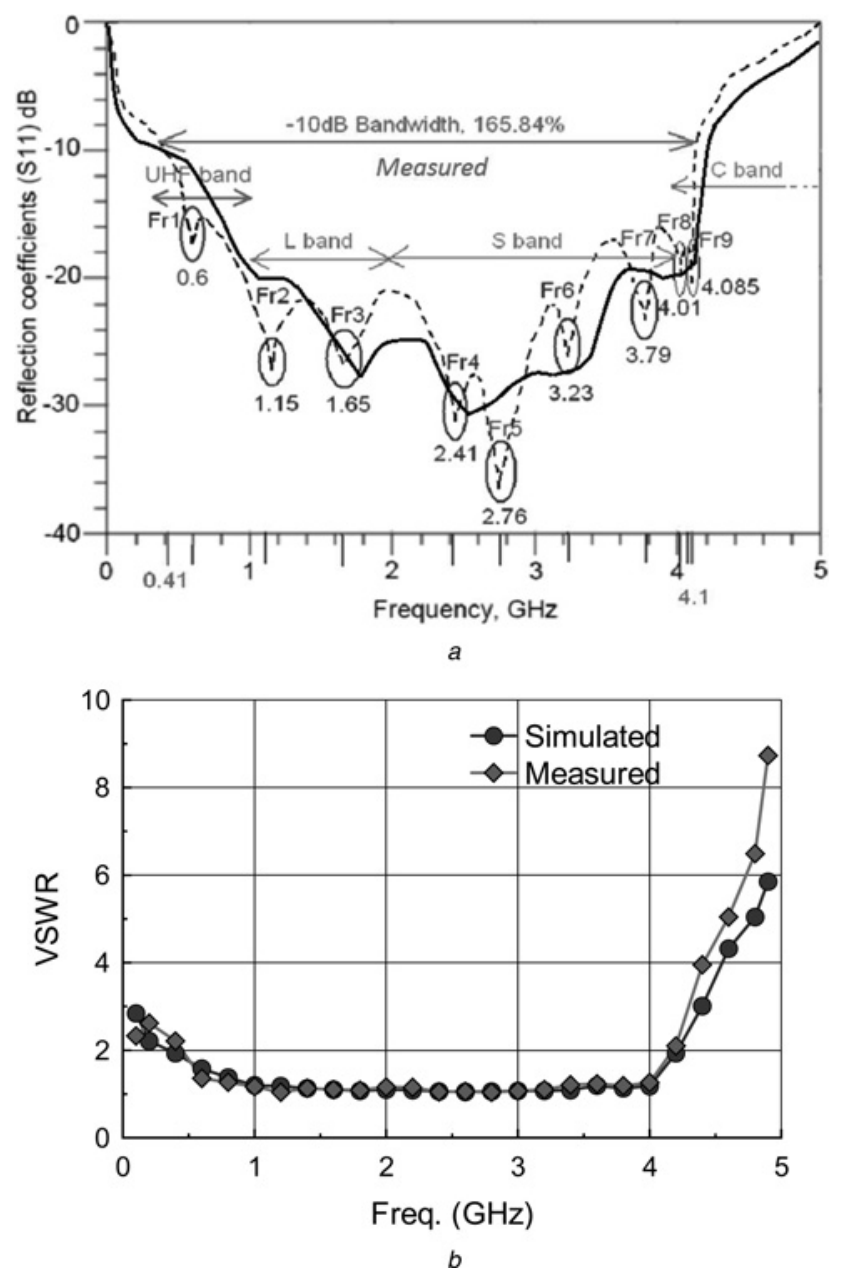

Fig. 11 Simulated and measured reflection coefficient, VSWR, group delay diagram, 2D radiation patterns and gain and efficiency curves of Antenna \#3 $a$ Simulated (solid line) and measured (dashed line) reflection-coefficient response $b$ Simulated (circular line) and measured (square line) voltage standing wave ratio response $c$ Simulated and measured group delay diagram

$d$ Measured 2D radiation patterns of Antenna \#3

$e$ Simulated (solid line) and measured (dashed line) gain and efficiency response of Antenna \#3

\section{Conclusions}

The feasibility of a planar antenna has been demonstrated using periodic array of E-shaped CAMC unit cells to realise small antennas that exhibit good radiation properties in the frequency range encompassing UHF to C-band. The antenna was optimised and the finalised antenna operates over $0.41-4.1 \mathrm{GHz}$; thus enabling communication with multiband multi-mode wireless communication systems. Realising an antenna that operates across a large frequency span is normally challenging with very small antennas especially at the lower frequency boundary. The measured gain and radiation efficiency of the proposed antenna at $410 \mathrm{MHz}$ is $1.05 \mathrm{dBi}$ and $32.5 \%$, respectively. The antenna has fractional bandwidth of $165.84 \%$, peak gain and radiation efficiency of $4.45 \mathrm{dBi}$ and $85.8 \%$, respectively, at the fifth resonance frequency of $2.76 \mathrm{GHz}$. The antenna has an overall size of $0.054 \lambda_{0} \times 0.047 \lambda_{0} \times 0.0021 \lambda_{0}$ at $410 \mathrm{MHz}$ or $40 \times 35 \times 1.6$ $\mathrm{mm}^{3}$. The planar nature of antenna enables easy integration with wireless transceivers.

\section{References}

1 Laure, H., Koubeissi, M., Mouhamadou, M., et al.: 'Compact and multiband dielectric resonator antenna with pattern diversity for multistandard mobile handheld devices', IEEE Trans. Antennas Propag., 2011, 59, pp. 4201-4208 


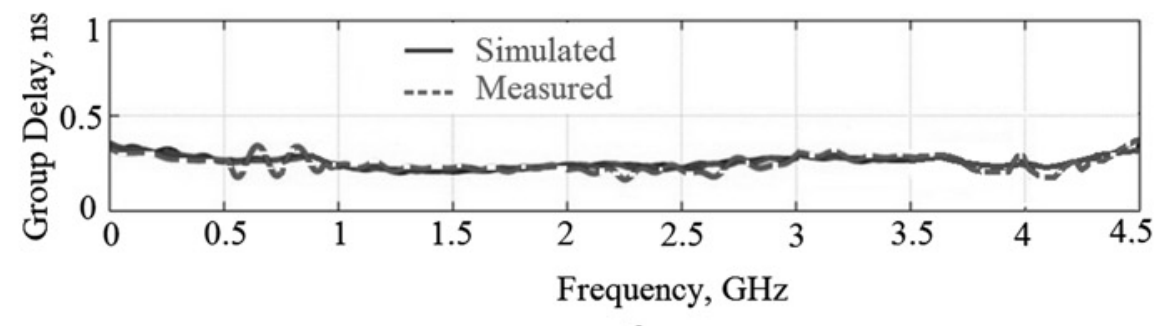

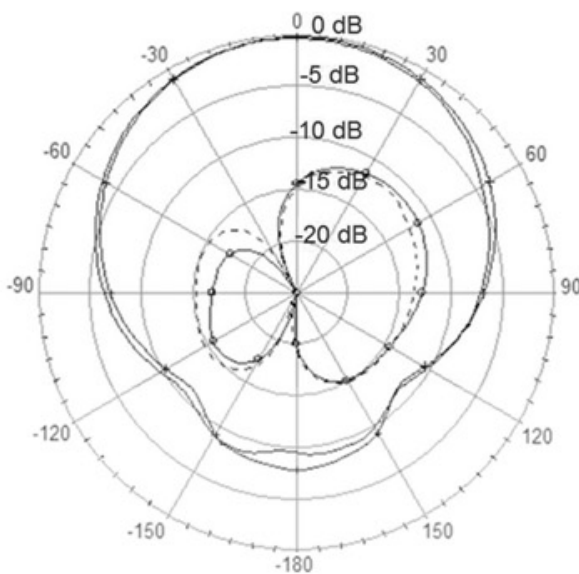

(a) $410 \mathrm{MHz}$

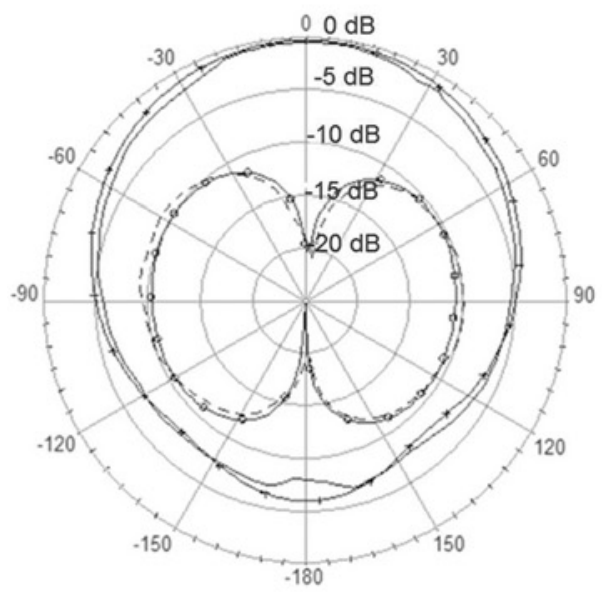

(a) $2.76 \mathrm{MHz}$

$\longrightarrow$ co-pol
$-x-p o l$

E-plane

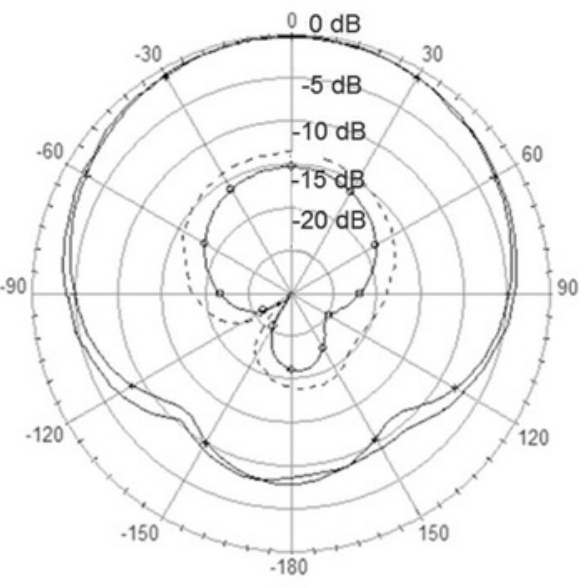

(a) $1.15 \mathrm{GHz}$

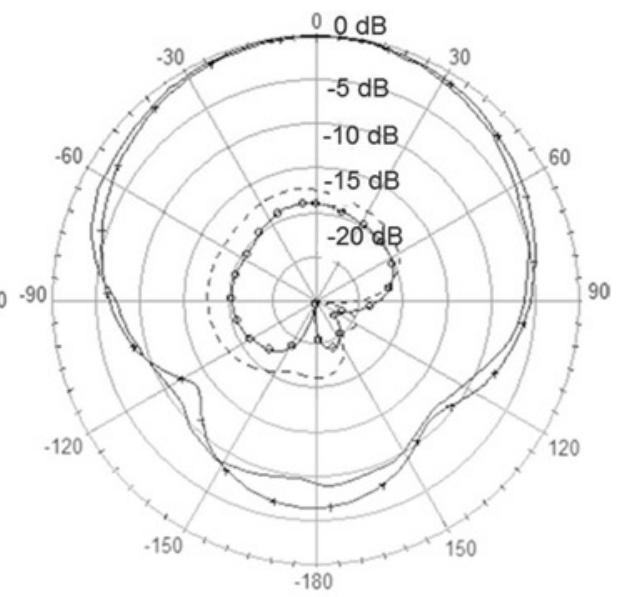

(a) $4.1 \mathrm{GHz}$

co-pol

H-plane

d

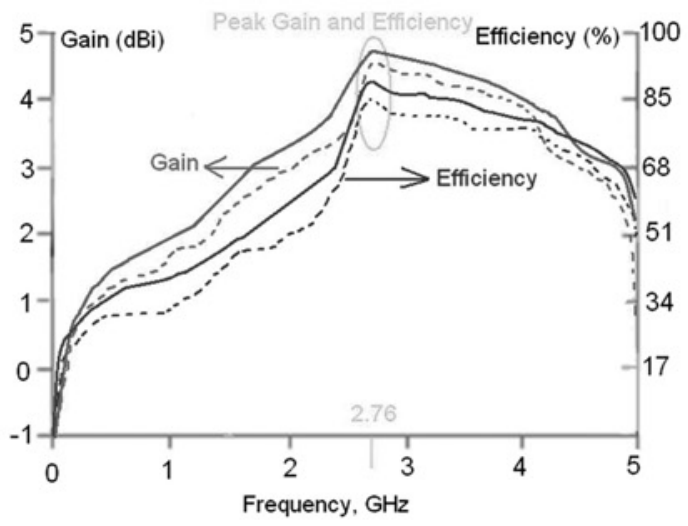

e

Fig. 11 Continued 
Table 4 Radiation characteristics of Antenna \#3

\begin{tabular}{|c|c|c|c|c|c|c|c|c|c|c|c|c|}
\hline \multicolumn{2}{|c|}{ Frequency, $\mathrm{GHz}$} & \multirow{2}{*}{$\frac{f_{\text {start }}: 0.41}{1.15}$} & \multirow{2}{*}{$\begin{array}{c}f_{r 1}: 0.6 \\
1.51\end{array}$} & \multirow{2}{*}{$\frac{f_{r 2}: 1.15}{2.05}$} & \multirow{2}{*}{$\begin{array}{c}f_{r 3}: 1.65 \\
2.9\end{array}$} & \multirow{2}{*}{$\begin{array}{c}f_{r 4}: 2.41 \\
3.63\end{array}$} & \multirow{2}{*}{$\begin{array}{c}f_{r 5}: 2.76(\max ) \\
4.75\end{array}$} & \multirow{2}{*}{$\begin{array}{c}f_{r 6}: 3.23 \\
4.53\end{array}$} & \multirow{2}{*}{$\begin{array}{c}f_{r 7}: 3.79 \\
4.21\end{array}$} & \multirow{2}{*}{$\begin{array}{c}f_{r 8}: 4.01 \\
4.08\end{array}$} & \multirow{2}{*}{$\begin{array}{c}f_{r 9}: 4.085 \\
3.91\end{array}$} & \multirow{2}{*}{$\begin{array}{r}f_{\text {end }}: 4 . \\
3.88\end{array}$} \\
\hline simulated & gain, dBi & & & & & & & & & & & \\
\hline & efficiency, \% & 34.2 & 37.1 & 40.3 & 51.8 & 65.0 & 88.6 & 84.8 & 79.2 & 77.8 & 75.2 & 73.7 \\
\hline \multirow[t]{2}{*}{ measured } & gain, $\mathrm{dBi}$ & 1.05 & 1.35 & 1.85 & 2.65 & 3.41 & 4.45 & 4.21 & 4.0 & 3.88 & 3.79 & 3.7 \\
\hline & efficiency, \% & 32.1 & 33.4 & 36.8 & 48.3 & 62.9 & 85.8 & 80.2 & 76.6 & 74.5 & 73.4 & 72.4 \\
\hline
\end{tabular}

Table 5 Measured performance of the proposed antennas

\begin{tabular}{|c|c|}
\hline \multicolumn{2}{|c|}{ Antenna \#1 } \\
\hline $\begin{array}{l}\text { dimensions } \\
\text { fractional bandwidth } \\
\text { maximum gain, } \mathrm{dBi} \\
\text { maximum efficiency, \% }\end{array}$ & $\begin{array}{c}0.036 \lambda_{0} \times 0.046 \lambda_{0} \times 0.0021 \lambda_{0} \text { at } 400 \mathrm{MHz} \text { or } 27 \times 35 \times 1.6 \mathrm{~mm}^{3} \\
140.74 \%(400 \mathrm{MHz}-2.3 \mathrm{GHz}) \\
2.21 \text { at } f_{r 4}=2.08 \mathrm{GHz} \\
51.4 \text { at } f_{r 4}=2.08 \mathrm{GHz}\end{array}$ \\
\hline \multicolumn{2}{|c|}{ Antenna \#2 } \\
\hline $\begin{array}{l}\text { dimensions } \\
\text { fractional bandwidth } \\
\text { maximum gain, } \mathrm{dBi} \\
\text { maximum efficiency, \% }\end{array}$ & $\begin{array}{c}0.047 \lambda_{0} \times 0.050 \lambda_{0} \times 0.0022 \lambda_{0} \text { at } 430 \mathrm{MHz} \text { or } 33 \times 35 \times 1.6 \mathrm{~mm}^{3} \\
149.11 \%(430 \mathrm{MHz}-2.95 \mathrm{GHz}) \\
3.12 \text { at } f_{r 6}=2.3 \mathrm{GHz} \\
52.7 \text { at } f_{r 6}=2.3 \mathrm{GHz}\end{array}$ \\
\hline \multicolumn{2}{|c|}{ Antenna \#3 } \\
\hline $\begin{array}{l}\text { dimensions } \\
\text { fractional bandwidth } \\
\text { maximum gain, } d B i \\
\text { maximum efficiency, \% }\end{array}$ & $\begin{array}{c}0.054 \lambda_{0} \times 0.047 \lambda_{0} \times 0.0021 \lambda_{0} \text { at } 410 \mathrm{MHz} \text { or } 40 \times 35 \times 1.6 \mathrm{~mm}^{3} \\
165.84 \%(410 \mathrm{MHz}-4.1 \mathrm{GHz}) \\
4.45 \text { at } f_{r 5}=2.76 \mathrm{GHz} \\
85.8 \text { at } f_{r 5}=2.76 \mathrm{GHz}\end{array}$ \\
\hline
\end{tabular}

Table 6 Specifications of the proposed antennas compared with recent multiband and broadband antennas

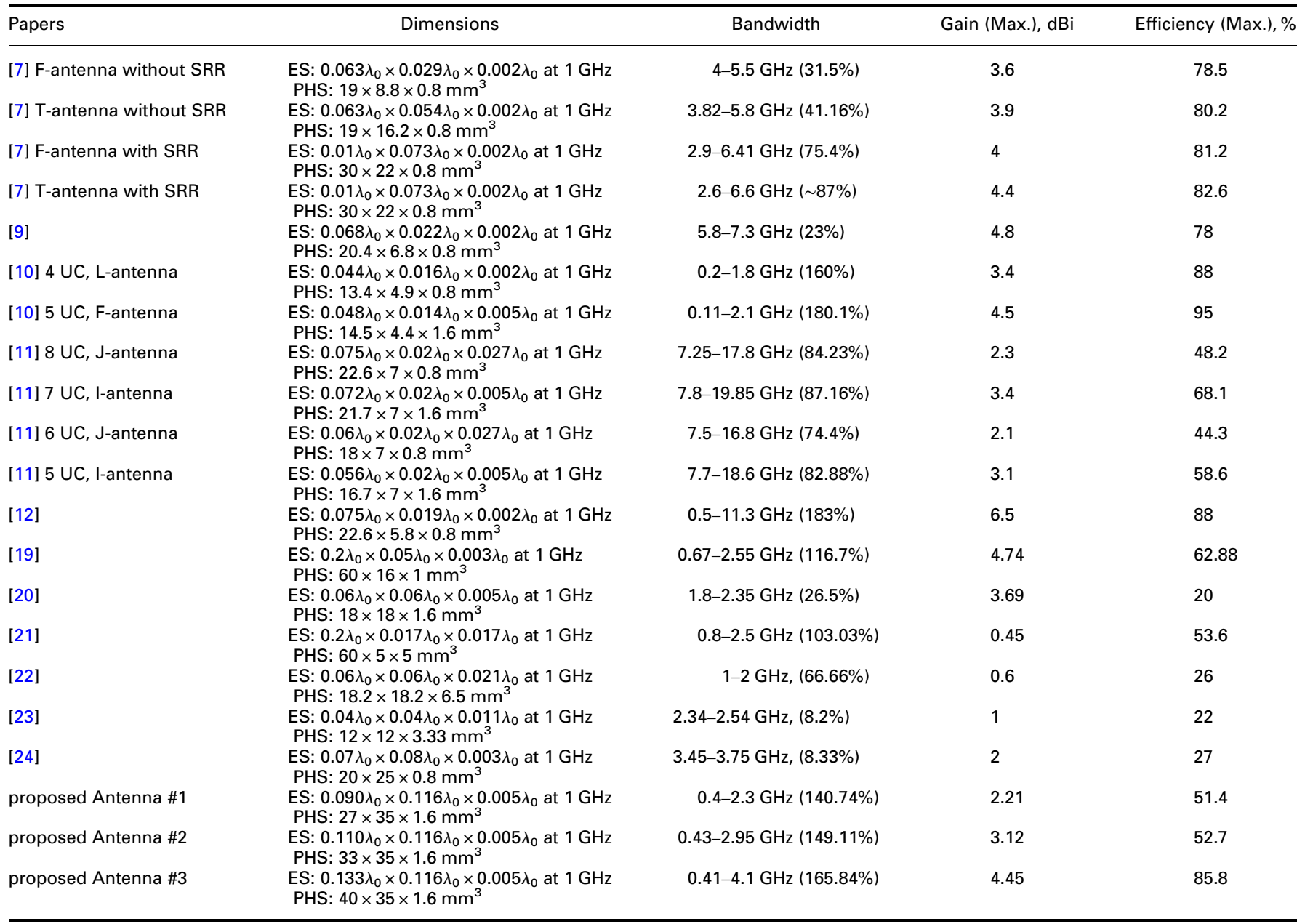

UC, unit cells; ES, electrically size; and PHS, physically size; SRR, Split Ring Resonator. 
2 Anguera, J., Font, G., Puente, C., et al.: 'Multifrequency microstrip patch antenna using multiple stacked elements', IEEE Microwave Wirel. Compon. Lett., 2003, 13, pp. 123-124

3 Yoon, J.H., Rhee, Y.C., Jang, Y.K.: 'Compact monopole antenna design for WLAN/WiMAX triple-band operations', Microw. Opt. Technol. Lett., 2012, 54, pp. $1838-1846$

4 Won-Gyu, J., Choi, J.-H.: 'Design of a wide and multiband aperture-stacked patch antenna with reflector', Microw. Opt. Technol. Lett., 2007, 49, pp. 2822-2824

5 Anguera, J., Andújar, A., Huynh, M.C., et al.: 'Advances in antenna technology for wireless handheld devices', Int. J. Antenna Propag., 2013, 2013, (2013), Article ID 838364 , p. 25

6 Caloz, C., Itoh, T.: 'Electromagnetic metamaterials: transmission line theory and microwave applications' (Wiley, New York, 2006)

7 Alibakhshi-Kenari, M., Naser-Moghadasi, M., Sadeghzadah, R.A.: 'Bandwidth and radiation specifications enhancement of monopole antennas loaded with split ring resonators', IET Microw. Antennas Propag., 2015, 9, (14), pp. 1487-1496

8 Ziolkowski, R.W., Erentok, A.: 'Metamaterial-inspired efficient electrically small antennas', IEEE Trans. Antennas Propag., 2008, 56, (3), pp. 691-707

9 Alibakhshi-Kenari, M., Naser-Moghadasi, M., Virdee, B.S., et al.: 'Compact antenna based on a composite right/left handed transmission line', Microw. Opt. Technol. Lett., 2015, 57, (8), pp. 1785-1788

10 Alibakhshi-Kenari, M., Naser-Moghadasi, M. Sadeghzadeh, R.A . 'Composite right-left-handed-based antenna with wide applications in very-high frequencyultra-high frequency bands for radio transceivers', IET Microw. Antennas Propag., 2015, 9, (15), pp. 1713-1726

11 Alibakhshi-Kenari, M.: 'Introducing the new wideband small plate antennas with engraved voids to form new geometries based on CRLH MTM-TLs for wireless applications', Int. J. Microw. Wirel. Technol., 2014, 6, (6), pp. 629-637

12 Alibakhshi-Kenari, M., Naser-Moghadasi, M.: 'Novel UWB miniaturized integrated antenna based on CRLH metamaterial transmission lines', AEU-Int. J. Electron. Commun., 2015, 69, (8), pp. 1143-1149

13 Antoniades, M.A., Eleftheriades, G.V.: 'A CPS leaky-wave antenna with reduced beam squinting using NRI-TL metamaterials', IEEE Trans. Antennas Propag., 2008, 56, (3), pp. 708-721
14 Abdalla, M.A.Y., Phang, K., Eleftheriades, G.V.: 'A steerable series-fed phased array architecture using tunable PRI/NRI phase shifters'. Int. Workshop on Antenna Technology: Small Antennas and Novel Metamaterials, Japan, 2008, pp. 83-86

15 Trentini, G.V.: 'Partially reflecting sheet arrays', IEEE Trans. Antennas Propag., 1956, AP-4, pp. 666-671

16 Goussetis, G., Guo, Y., Feresidis, A.P., et al.: 'Miniaturized and multi-band artificial magnetic conductors and electromagnetic band gap surfaces'. IEEE Antennas Propagation Society Int. Symp., 20-25 June 2004, vol. 1, pp. 293-296

17 Hiranandani, M.A., Yakovlev, A.B., Kishk, A.A.: 'Artificial magnetic conductors realised by frequency-selective surfaces on a grounded dielectric slab for antenna applications', IEE Proc., Microw. Antennas Propag., 2006, 153, (5), pp. $487-493$

18 Zhang, Z.: 'Antenna measurement' (Wiley-IEEE Press, 2011)

19 Luo, J., Gong, S., Duan, P., et al.: 'Small-size wideband monopole antenna with CRLH-TL for LTE mobile phone', Prog. Electromagn. Res. C, 2014, 50, pp. $171-179$

20 Abdalla, M.A., Awad, A.A., Hassan, K.M.: 'Wide band high selective compact metamaterial antenna for $2 \mathrm{GHz}$ wireless applications'. Antennas and Propagation Conf. (LAPC), November 2014, pp. 350-354

21 Li, Y., Zhang, Z., Zheng, J., et al.: 'Compact heptaband reconfigurable loop antenna for mobile handset', IEEE Antennas Wirel. Propag. Lett., 2011, 10, pp. $1162-1165$

22 Lee, C.J., Leong, K.M.K.H., Itoh, T.: 'Composite right/left-handed transmission line based compact resonant antennas for RF module integration', IEEE Trans. Antennas Propag., 2006, 54, (8), pp. 2283-2291

23 Lee, C.J., Leong, K.M.H., Itoh, T.: 'Broadband small antenna for portable wireless application'. Int. Workshop on Antenna Technology: Small Antennas and Novel Metamaterials, iWAT 2008, 2008, pp. 10-13

24 Yu, C.-C., Huang, M.-H., Lin, L.-K., et al.: 'A compact antenna based on MTM for WiMAX'. Asia-Pacific Microwave Conf. (APMC), Macau-China, December 2008 